\title{
Canadian Urological Association guidelines for followup of patients after treatment of non-metastatic renal cell carcinoma
}

Wassim Kassouf, MD ; Leonardo L. Monteiro, $\mathrm{MD}^{1}$; Darrel E. Drachenberg, $\mathrm{MD}^{2}$; Adrian S. Fairey, $\mathrm{MD}^{3}$; Antonio Finelli, $\mathrm{MD}^{4}$; Anil Kapoor, $\mathrm{MD}^{5}$; Jean-Baptiste Lattouf, $\mathrm{MD}^{6}$; Michael J. Leveridge, $\mathrm{MD}^{7}$; Nicholas E. Power, $\mathrm{MD}^{8}$; Frederic Pouliot, $\mathrm{MD}^{9}$; Ricardo A. Rendon, $\mathrm{MD}^{10}$; Robert Sabbagh, $\mathrm{MD}^{11}$; Alan So, $\mathrm{MD}^{12}$; Simon Tanguay, $\mathrm{MD}^{1}$; Rodney H. Breau, $\mathrm{MD}^{13}$

${ }^{1}$ Division of Urology, McGill University Health Centre, Montreal, QC; ${ }^{2}$ Section of Urology, University of Manitoba, Winnipeg, MB; ${ }^{3}$ Division of Urology, University of Alberta, Edmonton, AB; ${ }^{4}$ Division of Urology, University of Toronto, Toronto, ON; ${ }^{5}$ Division of Urology, McMaster University, Hamilton, ON; ${ }^{6}$ Division of Urology, University of Montreal, Montreal, QC; ${ }^{7}$ Department of Urology, Queen's University, Kingston, ON; ${ }^{8}$ Division of Urology, Western University, London, ON; ${ }^{9}$ Division of Urology, Laval University, Quebec City, QC; ${ }^{10}$ Department of Urology, Dalhousie University, Halifax, NS; ${ }^{11}$ Division of Urology, University of Sherbrooke, Sherbrooke, QC; ${ }^{12}$ Department of Urologic Sciences, University of British Columbia, Vancouver, BC; ${ }^{13}$ Division of Urology, University of Ottawa, Ottawa, ON; Canada

Cite as: Can Urol Assoc J 2018 May 31; Epub ahead of print. http://dx.doi.org/10.5489/cuaj.5462

\section{Published online May 31, 2018}

$* * *$

\section{Introduction and objectives}

Renal cell carcinoma (RCC) accounts for approximately 3\% of all malignancies. RCC is about twice as common in males. It is the seventh most common cancer and eleventh most common cause of cancer-related deaths among men. ${ }^{1,2}$ Cigarette smoking, obesity and hypertension are the most well established risk factors for sporadic RCC. . $^{3-6}$ Acquired cystic kidney disease (ACKD) is also a significant risk factor. ${ }^{7}$ Other studies have linked occupational exposure to RCC..$^{8-9}$ As many as 5\% of patients with RCCs are associated with germline mutations. There are a number of different hereditary diseases that are associated with RCC, including von Hippel-Lindau (VHL), hereditary papillary renal carcinoma (HPRC), Birt-Hogg-Dubé (BHD), hereditary leiomyomatosis renal cell carcinoma (HLRCC), succinate dehydrogenase kidney cancer (SHD-RCC), tuberous sclerosis complex (TSC), and Cowden's disease. ${ }^{10-14}$ There are different options for management of patients with clinically localized renal masses suspicious for RCC including active surveillance, ablation, and surgery. Comparing the nonsurgical with the surgical approach (partial or radical nephrectomy) for small renal masses, the surgical approach may be associated with better oncological outcomes based on large observational studies. ${ }^{15-18}$ However, no prospective randomized studies have been completed. 
Patients with newly diagnosed RCC are living longer after diagnosis, largely due incidental diagnoses and subsequent migration to earlier stages of disease. ${ }^{4}$ Surveillance after treatment is important since some patients are at high risk of asymptomatic cancer recurrence and these recurrences may respond better to treatment if detected early.

Observation remains the standard of care after nephrectomy. Surveillance protocols after treatment of the primary RCC tumour focus on oncological control, functional preservation, and survivorship. Publications that address surveillance after surgical extirpation are based on retrospective analysis, including some larger multicenter studies and well-designed controlled studies. ${ }^{19}$ There are no randomized trials of surveillance strategies, but an evidence based approach to follow up can be achieved by assessing the timing and location of RCC recurrence in a risk stratified manner. This updated guideline attempts to provide some clarity and guidance for the practicing urologist based on the current literature.

\section{Methods}

A systematic search of the PubMed and MEDLINE database was conducted. The searches were limited to English language publication. The main search terms used to identify eligible studies from database combined patient terms (renal or kidney carcinoma/tumour/neoplasm/cancer), intervention terms (radical nephrectomy, partial nephrectomy, nephron sparing surgery, ablation), and followup. Where possible, levels of evidence (LE) and grades of recommendations (GR) are provided employing the International Consultation on Urologic Disease (ICUD)/World Health Organization (WHO) modified Oxford Centre for Evidence-based Medicine grading system. ${ }^{20}$ The level of evidence was summarized according to the following: Level 1: Systematic review of randomized controlled trials (RCT); Level 2: Individual RCT, including lowquality RCT; Level 3: Controlled cohort; Level 4: Case-control studies or case series; Level 5: Expert opinion, mechanism based reasoning. Based on these levels of evidence, we have graded recommendations as follows: Grade A: usually consistent with level 1 studies; Grade B: consistent with level 2 or 3 studies or extrapolations from level 1 studies; Grade C: level 4 studies or extrapolations from level 2 or 3 studies; Grade D: level 5 evidence or inconsistent/inconclusive studies of any level.

The present guideline was organized into 3 major topics: rationale for surveillance, prognostic variables, and stage stratified surveillance recommendations. The main objective is to present the rationale and guide the post-treatment followup in patients with localized and locally advanced renal cell carcinoma.

\section{Rationale for surveillance}

Surveillance after treatment allows the urologist to monitor for postoperative complications, renal function, local recurrence, recurrence in the contralateral kidney, and development of metastases. Surveillance is usually accomplished with physical examination, radiologic imaging, and serum biochemistry testing. 
Chronic kidney disease (CKD) is recognized as a public health problem worldwide with prevalence between 8 and 16\%, and potentially associated with progression to end-stage renal disease (ESRD), cardiovascular disease and increased mortality rates. $^{21,22}$ Decreased kidney function refers to a decreased glomerular filtration rate (eGFR less than $60 \mathrm{ml} / \mathrm{min} / 1.73 \mathrm{~m}^{2}$ ), which is usually estimated (eGFR) using serum creatinine and one of several available equations. ${ }^{23}$ Huang et al, showed in a retrospective study that $26 \%$ of patients with solitary small renal mass $(\leq 4 \mathrm{~cm})$ surgically managed had CKD on the basis of Modification of Diet in Renal Disease equation. ${ }^{24}$ Several retrospective studies have demonstrated impairment of renal function after treatment for RCC; radical nephrectomy (RN) is a significant risk factor for the development of CKD. ${ }^{25-27}$ Renal function decreases post-operatively and usually improves over time until a new baseline is achieved in approximately 3 to 6 months. ${ }^{28}$ The aim of renal function surveillance is to prevent or delay CKD and avoid dialysis. Renal function and postoperative complications are commonly assessed by history, physical examination, and measurement of serum creatinine and hemoglobin at 4-6 weeks post surgery. Long-term monitoring of serum creatinine, eGFR, and proteinuria is recommended particularly in patients with compromised renal function prior to surgery or significant decrease in eGFR after surgery. Consideration for referral to a nephrologist if eGFR $<45 \mathrm{ml} / \mathrm{min} / 1.73 \mathrm{~m}^{2}$ or progressive CKD develops after surgery, especially if associated with proteinuria (Level of evidence: 2; Grade B). ${ }^{29-31}$

Radiologic imaging plays an important role at diagnosis for renal mass as well as followup after treatment for RCC. Surveillance in patients after treatment of RCC should be adapted and based on known independent predictors of postoperative recurrence to optimize the use of radiologic imaging. This understanding would avoid over surveillance of patients at low risk for relapse and under surveillance for those at high risk. It would also avoid unnecessary radiation exposure from radiologic imaging such as CT since theoretically it can be associated with an increased risk of secondary malignancies. ${ }^{32,33}$ Furthermore, a risk-adapted approach may also decrease the cost of surveillance on the health care system. ${ }^{34-36}$ Early diagnosis of local and contralateral kidney recurrence (incidence $<2 \%$ ) is useful since the majority of these patients can be cured with treatment (Level of evidence 4; Grade C). ${ }^{37-39}$ Risk factors for ipsilateral renal recurrence are positive surgical margins, tumour multifocality, higher tumour stage, and higher tumour grade. ${ }^{40}$ Tumours that develop in the contralateral kidney are more likely amendable to nephron-sparing treatments when detected earlier. Patients undergoing surgery for symptomatic recurrences have a higher rate of incomplete resection of recurrence, positive surgical margins and worse survival compared to surgery without symptoms. ${ }^{41-43}$ Extensive tumour recurrence reduces the possibility of complete surgical resection, which is standard therapy for patients with local recurrence or resectable solitary metastasis. Furthermore, an early diagnosis of metastatic disease relapse may enhance efficacy of systemic therapy or allow for metastasectomy if the tumour burden is low. Therefore, this supports the rationale for 
surveillance of patients to detect recurrences and metastases early when they are more likely to be successfully treated (Level of evidence 4; Grade C).

\section{Prognostic variables}

Predictors of disease relapse after surgical extirpation can be classified into anatomical (TNM classification system), histological, clinical, and molecular. ${ }^{44,45}$ Tumour grade, local extent of the primary tumour, presence of nodal metastasis, and histological subtype are predictors of the disease relapse (Level of Evidence 3). ${ }^{41,46-48}$ As such, these variables should be noted because they contribute to important prognostic information.

Histological subtype is a significant predictor of survival and recurrence, regardless of type of surgical resection or tumour stage. RCC with collecting duct carcinoma, medullary carcinoma, tumour with elements of sarcomatoid and rhabdoid dedifferentiation exhibit higher metastatic potential. Localized chromophobe and papillary RCC type 1 portend a better prognosis. ${ }^{49,50}$ Fuhrman nuclear grade is another important histological prognostic where higher grade is associated with worse prognosis in clear cell RCC (Level of Evidence 4). ${ }^{51-53}$

Clinical factors associated with prognosis include performance status (ECOG), the presence of symptoms (localized or systemic), cachexia, anemia, platelet count, elevated erythrocyte sedimentation rate, and primary tumour characteristics (tumour size, histologic coagulative necrosis, DNA ploidy) have also been shown to be associated with outcome (Level of Evidence 4). ${ }^{41,54-57}$

Molecular markers including carbonic anhydrase IX, hypoxia inducible factor, Ki67, p53, phosphatase and tensin homolog (PTEN), regulator of apoptosis Bcl-2, Ecadherins, C-reactive protein (CRP), microRNAs (miR-21 and miR-126) and others have demonstrated potential utility as prognostic markers, and vascular endothelial growth factor (VEGF) as predictive biomarker. ${ }^{58}$ Higher level of PD-L1 expression has been linked with a negative prognostic factor in RCC. The role of molecular markers in RCC is expansive and can range from aiding pathologic diagnosis, understanding the histogenesis of renal tumour, classifying new entities, and choosing appropriate therapy in patients who present with advanced disease, to the more investigative arena of elucidating predictive and prognostic behaviour of renal neoplasm. However, use of molecular markers is not recommended in the routine clinical setting (Grade C). ${ }^{59-65}$

\section{Surveillance}

Intensity and type of surveillance should vary depending on the risk of developing recurrence or metastases. The Canadian guidelines for surveillance after nephrectomy for nonmetastatic renal cell carcinoma is risk stratified based on pathologic stage, but some patients may benefit from more or less intensive surveillance based on other risk factors presented above. There are several nomograms and scoring systems that combine different prognostic factors. ${ }^{66-69}$ They classify patients into risk of relapse, progression, and survival. Although some of these nomograms have already been validated, they have not being widely used in routine clinical practice. Most of them 
are used to enrol patients in clinical trials. In the absence of randomized studies, surveillance recommendations are based on large nonrandomized cohorts with longterm followup. To evaluate recurrence in the lung, routine chest $\mathrm{x}$-ray is recommended. In higher risk patients, $\mathrm{CT}$ of the chest may be performed due to the higher sensitivity of this test compared to chest $x$-ray (Level of evidence 5; Grade D). To evaluate abdominal recurrences, CT of the abdomen and pelvis is recommended, particularly in cases of tumour-associated symptoms; an abdominal ultrasound may be performed for lower risk patients (pT1 and pT2) (Level of evidence 4; Grade C). CT head or bone scan is not routinely recommended unless clinically indicated (Level of evidence 4; Grade C). Magnetic resonance imaging (MRI) has presented acceptable accuracy to detect musculoskeletal and lymph node metastases, however, lower sensitivity to detect pulmonary metastases when compared to $\mathrm{CT} .{ }^{70} \mathrm{MRI}$ can be used to reduce radiation exposure from x-ray and CT during followup after treatment for renal cancer since MRI does not involve the use of ionizing radiation. The use of gadolinium based contrast agent in the MRI should be handled with caution because there is a slight chance of developing nephrogenic systemic fibrosis mainly in patients with severe renal failure. Positron emission tomography-computerized tomography (PET-CT) is a nuclear imaging modality with the ability to characterize molecular processes noninvasively during a fast whole-body scan. ${ }^{18}$ F-fluorodeoxyglucose (FDG) is the most common PET-CT radiotracer used in urology field. FDG PET-CT has a lower sensitivity compared to enhanced CT for primary diagnosis of renal masses. However, ${ }^{18} \mathrm{~F}$-Sodium fluoride PET-CT may have an advantage over conventional modalities in bone and musculoskeletal metastases. It is more sensitive at detecting RCC skeletal metastases than bone scintigraphy or CT. ${ }^{71,72}$ Currently, PET-CT is not a standard exam for diagnosis, staging, or surveillance in RCC.

\section{Recurrence patterns for pT1 tumours (Low Risk)}

Cohort studies have shown less than $7 \%$ of patients develop recurrences. The mean time to recurrence is 56 months and almost half of all recurrences are detected beyond 5 years following RN. ${ }^{73,74}$ Among several series, the local recurrence for $\mathrm{T} 1$ lesions is approximately $2 \%$. Local recurrence is more common for larger tumours following partial nephrectomy or tumour ablation compared to radical nephrectomy.

A population-based study showed occurrence of metastases or local recurrence in 5\% of patients with T1a and 15\% for T1b during 5 years of followup after RN or $\mathrm{PN}$. The incidence of distant metastases was higher than local recurrence, regardless of surgical approach. Concerning all stages of RCC, the most common locations of the first recurrence were lung (54\%), lymph nodes (22\%), bone (20\%), and liver (15\%). ${ }^{75}$ Other population-based studies have found similar results. ${ }^{76}$ Chin et al ${ }^{77}$ reported that tumour stage plays an important role in timing of recurrence, with T1 tumours generally recurring between 3 and 4 years following resection.

Similarly, a Canadian group has shown that median time to recurrence was 35 months (range 2-93) and only $0.9 \%$ had asymptomatic, isolated abdominal relapse at 13,66 , 
and 93 months postoperatively. ${ }^{78}$ Lam et al reported that following nephrectomy, median time to recurrence was 28.9 months (mean \pm SD $26.5 \pm 17.1$ ); the median time for chest and abdominal recurrence was 23.6 and 32 months, respectively. ${ }^{79}$ Among several studies regarding RCC surveillance, the latest postnephrectomy recurrence in the lungs, abdomen, and bone was approximately 6 years, 8 years, and 12 years, respectively. ${ }^{75-78}$ In a cohort from a single center, most kidney cancer patients treated for lung metastasis were diagnosed with metachronous lesions with the following features: solitary mass, one affected lung, and measured more than $2 \mathrm{~cm}$. Multivariate analysis confirmed a significant effect of radical surgery on the survival in these pateints. ${ }^{80}$ Unlike metastases to the abdomen and thorax, metastases to brain and bone were symptomatic in $98.2 \%$ and $90.5 \%$, respectively. These lesions become symptomatic quickly. ${ }^{81}$

In general, late recurrence beyond 5 years after nephrectomy for localized RCC can occur in $2 \%$ to $10 \%$ of patients, and some cases after 9 years from the initial treatment. Most recurrences are distant rather than local. ${ }^{82-84}$ The largest study evaluating relapse after 5 years following nephrectomy demonstrated lymphovascular invasion, Furhman grade 3 or 4, and pathologic tumour stage $>$ pT1 as independent predictors of late recurrence. In addition, late recurrence was approximately $2.6 \%, 5 \%$, 9\%, 10\%, 11\% and 22\% for T1a, T1b, T2a, T2b, T3a and T3b respectively. ${ }^{82}$

Regarding nephron-sparing surgery for RCC a retrospective study showed $5.1 \%$ recurrence rate (2.7\% pT1a and $12.7 \%$ pT1b), 61\% relapses were diagnosed within the first 24 months following surgery (median time to relapse was 14.3 months). Multifocal or bilateral lesions and pathological stage higher than T1a were independent predictors of relapse on multivariate competing risk regression analysis. ${ }^{36}$

Recommended surveillance (Table 1) will include blood biochemistry and chest $\mathrm{x}$ ray (CXR) annually following surgery. Abdominal CT, MRI or US is recommended at 24 and 60 months (Level of evidence 4; Grade $C$ ). Ultrasound is less sensitive than CT, however its use justifiable and cost effective in patients with a minimal risk of abdominal recurrence and lower body mass index (BMI). Followup is the same for partial nephrectomy for $<4 \mathrm{~cm}$ lesions since the local recurrence rates in this population are similar to radical nephrectomy (Level of evidence 2; Grade B). CT abdomen at 3-12 months postoperative for patients treated with partial nephrectomy to evaluate the residual baseline renal appearance is optional (Level of evidence 4; Grade C). Radiographic screening for brain and bone metastases is not recommended in asymptomatic patients (Level of evidence 4; Grade C). Routine imaging beyond 5 years is optional and can be risk-adapted (Grade $D$ ).

\section{Recurrence patterns for pT2 tumours (Intermediate Risk)}

Several series have reported recurrences after a mean time of 24 - 35 months (range 182). ${ }^{73-75}$ Dabestani et al ${ }^{75}$ reported $35 \%$ recurrence rate after mean followup duration of 5 years in a population-based study of patients with $\mathrm{T} 2$ disease who underwent $\mathrm{RN}$ or PN. Retrospective analysis of single institution with similar followup showed $16 \%$ of recurrence, diagnosed between 24 and 57 months after $\mathrm{RN}$, and the lung was the main 
site of recurrence. ${ }^{85}$ The Canadian group reported a median time to recurrence of 25 months (range 3-95) and 50\% were asymptomatic. ${ }^{78}$ Lam et al showed that median time to recurrence was 17.8 months (mean \pm SD $25.5 \pm 23.9$ ). ${ }^{79}$ Among several studies regarding RCC surveillance, the latest post-nephrectomy recurrence in the lungs, abdomen, and bones was approximately 8 years, 8 years, and 12 years, respectively. ${ }^{75-}$ ${ }^{78}$ Recommended surveillance (Table 1 ) will include clinical assessment, blood biochemistry, and CXR (or chest CT) every 6 months for 3 years then yearly. Abdominal CT, MRI or US recommended at 12, 24, 36, 60 months (Level of evidence: 4; Grade $\mathrm{C}$ ). Routine imaging beyond 5 years is at the discretion of the treating physician.

\section{Recurrence patterns for pT3 / pT4 tumours and N+ (High Risk)}

The median time to recurrence in this cohort is approximately 21 months (range 2101). ${ }^{73}$ Dabestani et al reported recurrence rates of $42 \%$ and $47 \%$ for patients with T3 and T4 disease, respectively. ${ }^{75}$ Tumours classified as T3 generally recurred between 17 and 28 months. ${ }^{77}$ Lam et al presented in this group that median time to recurrence was 9.5 months (mean \pm SD $21.9 \pm 26.2$ ). ${ }^{79}$ Stewart et al reported $28 \%$ of patients developed recurrence after a median of 13.9 months (range 10-68.3) ${ }^{86}$ In a multiinstitutional cohort of 176 patients with pathological T3 disease (pT3), 26\% of patients developed recurrence (24\% of patients developed metastatic disease and $2 \%$ of patients developed an isolated local recurrence) after median followup 22.6 months (range 0.2 75). Lung (70\%), bone (39\%), and lymph nodes (30\%) were the most common sites of metastases. ${ }^{87}$ The recurrence rate for these group of patients was $15 \%, 30 \%$, and $53 \%$ within 1,3 , and 5 years. ${ }^{88}$ Among several studies regarding RCC surveillance, the latest postnephrectomy recurrence in the lungs, abdomen, and bone was approximately 12 years, 6 years, and 5 years, respectively. ${ }^{75-78}$ The presence of lymph node metastases is associated with dismal prognosis ${ }^{89}$ with a median survival of only 20.4 months. ${ }^{90}$

Recommended surveillance (Table 1) will include clinical assessment, blood biochemistry, and CXR (or chest CT) within 3 months after surgery and every 6 months for 3 years then yearly. Abdominal CT or MRI recommended at 6, 12, 18, 24, 36, 60 months then every 2 years (Level of evidence: 4; Grade $C$ ). In cases of lymph node positive disease, abdominal CT or MRI is recommended at 3 and 6 months, then every 6 months for 3 years then yearly (Level of evidence 4; Grade C).

\section{Followup after ablation}

Ablation is an option to treat selected patients with small renal mass, usually patients with clinical T1a RCC. There are several settings where ablation can be an option or recommended such as patients with high surgical risk, complex mass in a solitary kidney, prior partial nephrectomy, and multifocal, bilateral RCC or patient preference. ${ }^{91,92}$ Patients who have undergone ablation therapy due to RCC should be followed with contrast-enhanced radiologic imaging (MRI or CT) to assess for residual enhancing disease and post procedure complication. The success of this procedure is 
defined by two types of imaging findings which are related to the zones of decreased perfusion, and the signal intensity (at MRI imaging), or attenuation (at CT). ${ }^{93}$ Ablated tumour may be larger than the pre-treatment size in the imaging promptly performed after the procedure due to extension of treatment beyond of its margin. After thermal ablation, the zone of ablation is usually seen as an area of hypoattenuation on computed tomography and is generally hypointense at T2-weighted magnetic resonance imaging and iso - to hyperintense at T1-weighted imaging relative to renal parenchyma. The ablation zone frequently involutes over time. Residual tumour after thermal ablation is most common at the margin of the ablation zone and often seen as nodular or crescent-shaped areas of contrast enhancement. ${ }^{94}$ Renal tumours successfully treated with RFA demonstrate no contrast enhancement. However, they do not regress significantly in size. ${ }^{95}$ Meanwhile, renal tumours successfully treated with cryoablation may demonstrate reduction in size or complete resolution, or scar formation. ${ }^{93}$ Definition of successful after RFA for small renal masses based only in radiographic imaging has provoked some debate. Nevertheless, radiologic imaging has remained the main tool to follow patients after ablation therapy. Meta-analysis evaluating cryoablation and RFA showed local tumour recurrence in $13 \%$ of patients and $2 \%$ of patients developed metastasis. ${ }^{96}$ A cohort of cT1a patients treated with RFA demonstrated good response in $74 \%$ of patients whereas $8 \%$ had partial response and $18 \%$ failure response within mean 30.6 months of followup (range $4-60$ ). ${ }^{97}$ Large single center series have shown failure rate of approximately $10 \%$ to cryoablation and radiofrequency. ${ }^{98,99}$ Several series has shown postoperative complications after ablation to treat RCC, ranges from 11\% to 23\% (Level of evidence 3). ${ }^{100-102}$ Matin et al. reviewed treatment and followup information of 616 patients from 7 institutions who underwent RFA or cryoablation for renal masses, and reported that most incomplete treatments (70\%) were detected within the first 3 months following treatment. ${ }^{103}$ Recommended surveillance for ablated cT1a lesions (Table 1) will include clinical assessment, blood biochemistry, abdominal imaging (CT or MRI) at 3, 6, and 12 months then annually thereafter for up to 5 years. Chest $x$-ray recommended annually during followup (Level of evidence 4; Grade C). If pretreatment biopsy demonstrated oncocytoma and imaging post ablation shows treatment success, routine imaging beyond one year is not recommended (Level of evidence 5; Grade D). 


\section{References}

1. Siegel RL, Miller KD, Jemal A. Cancer Statistics, 2016. CA Cancer J Clin 2016;66:7-30.

2. Lucca I, Klatte T, Fajkovic H, et al. Gender differences in incidence and outcomes of urothelial and kidney cancer. Nat Rev Urol 2015;12:585-92.

3. Qayyum T, Oades G, Horgan P, Aitchison, et al. The epidemiology and risk factors for renal cancer. Curr Urol 2013;6:169-74.

4. Chow WH, Dong LM, Devesa SS. Epidemiology and risk factors for kidney cancer. Nat Rev Urol 2010;7:245-57.

5. Macleod LC, Hotaling JM, Wright JL, et al. Risk Factors for Renal Cell Carcinoma in the VITAL Study. J Urol 2013;190:1657-61.

6. Sanfilippo KM, McTigue KM, Fidler CJ, et al. Hypertension and Obesity and the Risk of Kidney Cancer in 2 Large Cohorts of US Men and Women. Hypertension 2014;63:934-41.

7. Truong LD, Krishnan B, Cao JT, et al. Renal neoplasm in acquired cystic kidney disease. Am J Kidney Dis 1995;26:1-12.

8. Mariusdottir E, Ingimarsson JP, Jonsson E, et al. Occupation as a risk factor for renal cell cancer: a nationwide, prospective epidemiological study. Scan J Urol 2016;50:181-5.

9. Karami S, Boffetta P, Stewart PS, et al. Occupational exposure to dusts and risk of renal cell carcinoma. Br J Cancer 2011;104:1797-803.

10. Chittiboina P, Lonser RR. Von Hippel-Lindau disease. Handb Clin Neurol 2015;132:139-56.

11. Yap NY, Rajandram R, Ng KL, et al. Genetic and chromosomal aberrations and their clinical significance in renal neoplasms. Biomed Res Int 2015;2015:476508. doi: 10.1155/2015/476508. Epub 2015 Sep 13.

12. Adeniran AJ, Shuc B, Humphrey PA. Hereditary renal cell carcinoma syndromes: clinical, pathologic, and genetic features. Am J Surg Pathol 2015;39: e1-e18. doi: 10.1097/PAS.0000000000000562.

13. Linehan WM. Genetic basis of kidney cancer: role of genomics for the development of disease-based therapeutics. Genome Res 2012;22:2089-100.

14. Byler TK, Bratslavsky G. Hereditary renal cell carcinoma: genetics, clinical features, and surgical considerations. World J Urol 2014;32:623-30.

15. Zini L, Perrotte P, Jeldres C, et al. A population-based comparison of survival after nephrectomy vs nonsurgical management for small renal masses. BJU Int 2009;103:899-904.

16. Pierorazio PM, Johnson MH, Patel HD, et al. Management of renal masses and localized renal cancer: systematic review and meta-analysis. J Urol 2016;196:989-99.

17. Van Poppel H, Da Pozzo L, Albrecht W, et al. A prospective, randomised EORTC intergroup phase 3 study comparing the oncologic outcome of 
elective nephron-sparing surgery and radical nephrectomy for low-stage renal cell carcinoma. Eur Urol 2011;59:543-52.

18. Tan HJ, Norton EC, Ye Z, et al. Long-term survival following partial vs radical nephrectomy among older patients with early-stage kidney cancer. JAMA 2012;307:1629-35.

19. Skolarikos A, Alivizatos G, Laguna P, et al. A Review on followup strategies for renal cell carcinoma after nephrectomy. Eur Urol 2007;51:1490-500.

20. University of Oxford, Graduate School in EBM and Research Methods, Centre for Evidence-based Medicine - Levels of Evidence 2009. Produced by Bob Phillips, Chris Ball, Dave Sackett, Doug Badenoch, Sharon Straus, Brian Haynes, Martin Dawes since November 1998. Updated by Jeremy Howick March 2009. http://www.cebm.net/index.aspx?o=1025. Accessed July 1, 2017.

21. Kates M, Badalato GM, McKiernan JM. Renal functional outcomes after surgery for renal cortical tumours. Curr Opin Urol 2011;21:351-5.

22. Go AS, Chertow GM, Fan D, et al. Chronic kidney disease and the risk of death, cardiovascular events, and hospitalization. $N$ Engl J Med 2004;351:1296-305.

23. Inker LA, Astor BC, Fox CH, et al. KDOQI US Commentary oh the 2012 KDIGO clinical practice guideline for the evaluation and management of CKD. Am J Kidney Dis 2014;63:713-35.

24. Huang WC, Levey AS, Serio AM, et al. Chronic kidney disease after nephrectomy in patients with renal cortical tumours: a retrospective cohort study. Lancet Oncol 2006;7:735-40.

25. Mashni JW, Assel M, Maschino A, et al. New chronic kidney disease and overall survival after nephrectomy for small renal cortical tumours. Urology 2015;86:1137-43.

26. Clark MA, Shikanov S, Raman JD, et al. Chronic kidney disease before and after partial nephrectomy. J Urol 2011;185:43-8.

27. Rendon RA, Mason R, Kapoor A, et al. The natural history of renal function after surgical management of renal cell carcinoma: Results from the Canadian Kidney Cancer Information System. Urol Oncol 2016;34:486.e1e7.

28. Chung JS, Son NH, Byun SS, et al. Trends in a renal function after radical nephrectomy: a multicentre analysis. BJU Int 2014;113:408-15.

29. Finelli A, Ismaila N, Bro B, et al. Management of Small Renal Masses: American Society of Clinical Oncology Clinical Practice Guideline. J Clin Oncol 2017;35:668-80.

30. Chronic Kidney Disease Prognosis Consortium, Matsushita K, van der Velde M, Astor BC, et al. Association of estimated glomerular filtration rate and albuminuria with all-cause and cardiovascular mortality: a collaborative 
meta-analysis of general population cohorts: a collaborative meta-analysis. Lancet 2010;375:2073-81.

31. Pettus JA, Jang TL, Thompson RH, et al. Effect of baseline glomerular filtration rate on survival in patients undergoing partial or radical nephrectomy for renal cortical tumours. Mayo Clin Proc 2008;83:1101-6.

32. Brenner DJ, Hall EJ. Computed tomography - an increasing source of radiation exposure. $N$ Engl J Med 2007;357:2277-84.

33. Chang SL, Cipriano LE, Harshman LC, et al. Cost-effectiveness analysis of nephron sparing options for the management of small renal masses. $J$ Urol 2011;185:1591-7.

34. Marconi L, Gorin MA, Allaf ME. Post partial nephrectomy surveillance imaging: an evidence-based approach. Curr Urol Rep 2015;16:23.

35. Lipsky MJ, Shapiro EY, Hruby GW, et al. Diagnostic radiation exposure during surveillance in patients with pT1a renal cell carcinoma. Urology 2013;81:1190-5.

36. Zargar-Shoshtari K, Kim T, Simon R, et al. Surveillance following nephronsparing surgery: an assessment of recurrence patterns and surveillance costs. Urology 2015;86:321-6.

37. Bani-Hani AH, Leibovich BC, Loshe CM, et al. Associations with contralateral recurrence following nephrectomy for renal cell carcinoma using a cohort of 2,352 Patients. J Urol 2005;173:391-4.

38. Chow JJ, Ahmed K, Fazili Z, et al. Solitary renal fossa recurrence of renal cell carcinoma after nephrectomy. Rev Urol 2014;16:76-82.

39. Thomas AZ, Adibi M, Borregales LD, et al. Surgical management of local retroperitoneal recurrence of renal cell carcinoma after radical nephrectomy. J Urol 2015;194:316-22.

40. Kapoor A, Bansal RK, Tanguay S, et al. Positive surgical margins during partial nephrectomy for renal cell carcinoma: Results from Canadian Kidney Cancer information system (CKCis) collaborative. Can Urol Assoc J 2017;11:182-7.

41. Psutka SP, Heidenreich M, Boorjian SA, et al. Renal fossa recurrence after nephrectomy for renal cell carcinoma: prognostic features and oncological outcomes. BJU Int 2017;119:116-27.

42. Paparel P, Bigot P, Matillon X, et al. Local recurrence after radical nephrectomy for kidney cancer: management and prediction of outcomes. a multi-institutional study. J Surg Oncol 2014;109:126-31.

43. Margulis V, McDonald M, Tamboli P, et al. Predictors of oncological outcome after resection of locally recurrent renal cell carcinoma. J Urol 2009;181:2044-51.

44. Volpe A, Patard JJ. Prognostic factors in renal cell carcinoma. World J Urol 2010;28:319-27. 
45. Sun M, Shariat SF, Cheng C, et al. Prognostic factors and predictive models in renal cell carcinoma: a contemporary review. Eur Urol 2011;60:644-61.

46. Lee HW, Jeon HG, Jeong BC, et al. Diagnostic and prognostic significance of radiologic node-positive renal cell carcinoma in the absence of distant metastases: a retrospective analysis of patients undergoing nephrectomy and lymph node dissection. J Korean Med Sci 2015;30:1321-7.

47. Borregales LD, Kim DY, Staller AL, et al. Prognosticators and outcomes of patients with renal cell carcinoma and adjacent organ invasion treated with radical nephrectomy. Urol Oncol 2016;34:237.e19-26. doi: 10.1016/j.urolonc.2015.11.020. Epub 2015 Dec 18.

48. Nguyen DP, Vertosick EA, Corradi RB, et al. Histological subtype of renal cell carcinoma significantly affects survival in the era of partial nephrectomy. Urol Oncol 2016;34:259.e1-8. doi: 10.1016/j.urolonc.2016.01.005. Epub 2016 Mar 2.

49. Patard JJ, Leray E, Rioux-Leclercq N, et al. Prognostic value of histologic subtypes in renal cell carcinoma: a multicenter experience. $J$ Clin Oncol 2005;23:2763-71.

50. Ljungberg B, Bensalah K, Canfield S, et al. EAU guidelines on renal cell carcinoma: 2014 Update. Eur Urol 2015;67:913-24.

51. Fuhrman SA, Lasky LC, Limas C. Prognostic significance of morphologic parameters in renal cell carcinoma. Am J Surg Pathol 1982;6:655-63.

52. Delahunt B, Sika-Paotonu D, Bethwaite PB, et al. Grading of clear cell renal cell carcinoma should be based on nucleolar prominence. Am J Surg Pathol 2011;35:1134-9.

53. Lang H, Lindner V, de Fromont M, et al. Multicenter determination of optimal interobserver agreement using the Fuhrman grading system for renal cell carcinoma: assessment of 241 patients with > 15-year followup. Cancer 2005;103:625-9.

54. Patard JJ, Leray E, Cindolo L, et al. Multi-Institutional validation of a symptom based classification for renal cell carcinoma. J Urol 2004;172:85862.

55. Kim HL, Han KR, Zisman A, et al. Cachexia-Like symptoms predict a worse prognosis in localized T1 renal cell carcinoma. J Urol 2004;171:18103.

56. Kim HL, Belldegrun AS, Freitas DG, et al. Paraneoplastic signs and symptoms of renal cell carcinoma: implications for prognosis. J Urol 2003;170:1742-6.

57. Bensalah K, Leray E, Fergelot P, et al. Prognostic value of thrombocytosis in renal cell carcinoma. J Urol 2006;175:859-63.

58. Golovastova MO, Korolev DO, Tsoy LV, et al. Biomarkers of renal tumours: the current state and clinical perspectives. Curr Urol Rep 2017;18:3. doi: 10.1007/s11934-017-0655-1. 
59. Poste G. Bring on the biomarkers. Nature 2011;469:156-7.

60. Sim SH, Messenger MP, Gregory WM, et al. Prognostic utility of preoperative circulating osteopontin, carbonic anhydrase IX and CRP in renal cell carcinoma. Br J Cancer 2012;107:1131-7.

61. Tan PH, Cheng L, Rioux-Leclercq N, et al. Renal tumours: diagnostic and prognostic biomarkers. Am J Surg Pathol 2013;37:1518-31.

62. Ngo TC, Wood CG, Karam JA. Biomarkers of renal cell carcinoma. Urol Oncol 2014;32:243-51.

63. Patard JJ, Kim HL, Lam JS, Dorey FJ, et al. Use of the University of California Los Angeles integrated staging system to predict survival in renal cell carcinoma: an international multicenter study. J Clin Oncol 2004;22:3316-22.

64. Barbieri CE, Chinnaiyan AM, Lerner SP, et al. The emergence of precision urologic oncology: a collaborative review on biomarker-driven therapeutics. Eur Urol 2017;71:237-46.

65. Iacovelli R, Nolè F, Verri E, et al. Prognostic role of PD-L1 expression in renal cell Carcinoma. A systematic review and meta-analysis. Target Oncol 2016;11:143-8.

66. Patard JJ, Kim HL, Lam JS, et al. Use of the University of California Los Angeles integrated staging system to predict survival in renal cell carcinoma: an international multicenter study. J Clin Oncol 2004;22:331622.

67. Zisman A, Pantuck AJ, Dorey F, et al. Improved prognostication of renal cell carcinoma using an integrated staging system. J Clin Oncol 2001;19:1649-57

68. Zigeuner R, Hutterer G, Chromecki T, et al. External validation of the Mayo Clinic stage, size, grade, and necrosis (SSIGN) score for clear-cell renal cell carcinoma in a single European centre applying routine pathology. Eur Urol 2010;57:102-9.

69. Karakiewicz PI, Briganti A, Chun FK, et al. Multi-institutional validation of a new renal cancer-specific survival nomogram. J Clin Oncol 2007;25:131622.

70. Platzek I, Zastrow S, Deppe PE, et al. Whole-body MRI in followup of patients with renal cell carcinoma. Acta Radiol 2010;51:581-9.

71. Gofrit ON, Orevi M. Diagnostic challenges of kidney cancer: a systematic review of the role of positron emission tomography-computerized tomography. J Urol 2016;196:648-57.

72. Gerety EL, Eisen T, Gallagher FA, et al. Prospective study evaluating the relative sensitivity of $18 \mathrm{~F}-\mathrm{NaF}$ PET/CT for detecting skeletal metastases from renal cell carcinoma in comparison to multidetector CT and 99mTcMDP bone scintigraphy, using an adaptive trial design. Ann Oncol 2015;26:2113-8. 
73. van Oostenbrugge TJ, Kroeze SG, Bosch JL, et al. The blind spots in followup after nephrectomy or nephron-sparing surgery for localized renal cell carcinoma. World J Urol 2015;33:881-7.

74. Leibovich BC, Blute ML, Cheville JC, et al. Prediction of progression after radical nephrectomy for patients with clear cell renal cell carcinoma: a stratification tool for prospective clinical trials. Cancer 2003;97:1663-71.

75. Dabestani S, Thorstenson A, Lindblad P, et al. Renal cell carcinoma recurrences and metastases in primary non-metastatic patients: a populationbased study. World J Urol 2016;34:1081-6.

76. Bianchi M, Sun M, Jeldres C, et al. Distribution of metastatic sites in renal cell carcinoma: a population-based analysis. Ann Oncol 2012;23:973-80.

77. Chin AI, Lam JS, Figlin RA, et al. Surveillance strategies for renal cell carcinoma patients following nephrectomy. Rev Urol 2006;8:1-7.

78. Stephenson AJ, Chetner MP, Rourke K, et al. Guidelines for the surveillance of localized renal cell carcinoma based on the patterns of relapse after nephrectomy. J Urol 2004;172:58-62.

79. Lam JS, Shvarts O, Leppert JT, et al. Postoperative surveillance protocol for patients with localized and locally advanced renal cell carcinoma based on a validated prognostic nomogram and risk group stratification system. J Urol 2005;174:466-72.

80. Matveev VB, Volkova MI, Turkin IN, et al. Surgical treatment of lung metastases of kidney cancer. Urologiia 2013;Jan-Feb:63-8.

81. Siddiqui SA, Frank I, Cheville JC, et al. Postoperative surveillance for renal cell carcinoma: a multifactorial histological subtype specific protocol. BJU Int 2009;104:778-85.

82. Brookman-May S, May M, Shariat SF, et al; Members of the CORONA project and the SATURN project. Features associated with recurrence beyond 5 years after nephrectomy and nephron-sparing surgery for renal cell carcinoma: development and internal validation of a risk model (PRELANE score) to predict late recurrence based on a large multicenter database (CORONA/SATURN Project). Eur Urol 2013;64:472-7.

83. Kim SP, Weight CJ, Leibovich BC, et al. Outcomes and clinicopathologic variables associated With late recurrence after nephrectomy for localized renal cell carcinoma. Urology 2011;78:1101-6.

84. Adamy A, Chong KT, Chade D, et al. Clinical characteristics and outcomes of patients with recurrence 5 years after nephrectomy for localized renal cell carcinoma. J Urol 2011;185:433-8.

85. Kwon SY, Jung JW, Kim BS, et al. Laparoscopic versus open radical nephrectomy in T2 renal cell carcinoma: long-term oncologic outcomes. Korean J Urol 2011;52:474-8. 
86. Stewart GD, Ang WJ, Laird A, et al. The operative safety and oncological outcomes of laparoscopic nephrectomy for T3 renal cell cancer. BJU Int 2012;110:884-90.

87. Nayak JG, Patel P, Bjazevic J, et al. Clinical outcomes following laparoscopic management of pT3 renal masses: A large, multi-institutional cohort. Can Urol Assoc J 2015;9:397-402.

88. Azawi NH, Tesfalem H, Mosholt KS, et al. Recurrence and survival in a Danish cohort with renal cell carcinoma. Dan Med J 2016;63.pii:A5208.

89. Capitanio U, Jeldres C, Patard JJ, et al. Stage-specific effect of nodal metastases on survival in patients with non-metastatic renal cell carcinoma. BJU Int 2009;103:33-7.

90. Babaian KN, Kim DY, Kenney PA, et al. Preoperative predictors of pathological lymph node metastasis in patients with renal cell carcinoma undergoing retroperitoneal lymph node dissection. J Urol 2015;193:1101-7.

91. Katsanos K, Mailli L, Krokidis M, et al. Systematic review and metaanalysis of thermal ablation versus surgical nephrectomy for small renal tumours. Cardiovasc Intervent Radiol 2014;37:427-37.

92. Pierorazio PM, Johnson MH, Patel HD, et al. Management of renal masses and localized renal cancer: systematic review and meta-analysis. J Urol 2016;196:989-99.

93. Ahmed M, Solbiati L, Brace CL, et al. Image-guided tumour ablation: standardization of terminology and reporting criteria - a 10-year update. $J$ Vasc Interv Radiol 2014;25:1691-705. e4. doi: 10.1016/j.jvir.2014.08.027. Epub 2014 Oct 23.

94. Kawamoto S, Solomon SB, Bluemke DA, et al. Computed tomography and magnetic resonance imaging appearance of renal neoplasm after radiofrequency ablation and cryoablation. Semin Ultrasound CT MR 2009;30:67-77.

95. Matsumoto ED, Watumull L, Johnson DB, et al. The radiographic evolution of radio frequency ablated renal tumours. $J$ Urol 2004;172:45-8.

96. Kunkle DA, Uzzo RG. Cryoablation or radiofrequency ablation of the small renal mass: a meta-analysis. Cancer 2008;113:2671-80.

97. Curry D, Yassin M, Thwaini A, et al. Radiofrequency ablation of renal cell carcinoma: a follow up of outcomes. Can J Urol 2014;21:7135-40.

98. Tanagho YS, Roytman TM, Bhavani SB, et al. Laparoscopic cryoablation of renal masses: single-center long-term experience. Urology 2012;80:307-14.

99. Psutka SP, Feldman AS, McDougal WS, et al. Long-term oncologic outcomes after radiofrequency ablation for T1 renal cell carcinoma. Eur Urol 2013;63:486-92.

100. Turdeau V. Larcher A, Boehm K, et al. Comparison of postoperative complications and mortality between laparoscopic and percutaneous local 
tumour ablation for T1a renal cell carcinoma: A population-based study. Urology 2016;89:63-7.

101. McClure TD, Chow DS, Tan N, et al. Intermediate outcomes and predictors of efficacy in the radiofrequency ablation of 100 pathologically proven renal cell carcinomas. J Vasc Interv Radiol 2014;25:1682-8.

102. Atwell TD, Carter RE, Schmit GD, et al. Complications following 573 percutaneous renal radiofrequency and cryoablation procedures. J Vasc Interv Radiol 2012;23:48-54.

103. Matin SF, Ahrar K, Cadeddu JA, et al. Residual and recurrent disease following renal energy ablative therapy: a multi-institutional study. J Urol 2006;176:1973-7. 
Figures and Tables

\begin{tabular}{|c|c|c|c|c|c|c|c|c|c|}
\hline Months postop & 3 & 6 & 12 & 18 & 24 & 30 & 36 & 48 & 60 \\
\hline \multicolumn{10}{|l|}{ Low-risk (pT1) } \\
\hline $\mathrm{Hx} \& \mathrm{PE}$ & & & $\mathrm{x}$ & & $\mathrm{x}$ & & $\mathrm{x}$ & $\mathrm{x}$ & $\mathrm{x}$ \\
\hline Blood test & & & $\mathrm{x}$ & & $\mathrm{x}$ & & $\mathrm{x}$ & $\mathrm{x}$ & $\mathrm{x}$ \\
\hline CXR & & & $\mathrm{x}$ & & $\mathrm{x}$ & & $\mathrm{x}$ & $\mathrm{x}$ & $\mathrm{x}$ \\
\hline $\begin{array}{l}\text { Abdominal } \\
\text { CT/MRI/US }\end{array}$ & & & & & $\mathrm{x}$ & & & & $\mathrm{x}$ \\
\hline \multicolumn{10}{|l|}{$\begin{array}{l}\text { Intermediate-risk } \\
\text { (pT2) }\end{array}$} \\
\hline Hx \& PE & & $\mathrm{x}$ & $\mathrm{x}$ & $\mathrm{X}$ & $\mathrm{x}$ & $\mathrm{x}$ & $\mathrm{x}$ & $\mathrm{x}$ & $\mathrm{x}$ \\
\hline Blood test & & $\mathrm{x}$ & $\mathrm{x}$ & $\mathrm{x}$ & $\mathrm{x}$ & $\mathrm{x}$ & $\mathrm{x}$ & $\mathrm{x}$ & $\mathrm{x}$ \\
\hline CXR or Chest CT & & $\mathrm{x}$ & $\mathrm{x}$ & $\mathrm{x}$ & $\mathrm{x}$ & $\mathrm{x}$ & $\mathrm{x}$ & $\mathrm{x}$ & $\mathrm{x}$ \\
\hline $\begin{array}{l}\text { Abdominal } \\
\text { CT/MRI/US }\end{array}$ & & & $\mathrm{x}$ & & $\mathrm{X}$ & & $\mathrm{x}$ & O & $\mathrm{x}$ \\
\hline \multicolumn{10}{|l|}{ High-risk (pT3-4)* } \\
\hline Hx \& PE & & $\mathrm{x}$ & $\mathrm{x}$ & $\mathrm{x}$ & $\mathrm{X}$ & $\mathrm{x}$ & $\mathrm{x}$ & $\mathrm{x}$ & $\mathrm{x}$ \\
\hline Blood test & & $\mathrm{x}$ & $\mathrm{x}$ & $\mathrm{x}$ & $\mathrm{x}$ & $\mathrm{X}$ & $\mathrm{x}$ & $\mathrm{x}$ & $\mathrm{x}$ \\
\hline CXR or Chest CT & & $\mathrm{x}$ & $\mathrm{x}$ & $\mathrm{x}$ & $\mathrm{x}$ & $\mathrm{x}$ & $\mathrm{x}$ & $\mathrm{x}$ & $\mathrm{x}$ \\
\hline Abdominal CT/MRI & & $\mathrm{x}$ & $\mathrm{x}$ & $\mathrm{x}$ & $\mathrm{x}$ & & $\mathrm{x}$ & & $\mathrm{x}$ \\
\hline $\begin{array}{l}\text { Very high-risk* } \\
(\mathrm{pTxN}+)\end{array}$ & & & & & & & & & \\
\hline Hx \& PE & $\mathrm{X}$ & $\mathrm{x}$ & $\mathrm{x}$ & $\mathrm{x}$ & $\mathrm{X}$ & $\mathrm{x}$ & $\mathrm{X}$ & $\mathrm{x}$ & $\mathrm{X}$ \\
\hline Blood test & $\mathrm{x}$ & $\mathrm{x}$ & $\mathrm{x}$ & $\mathrm{x}$ & $\mathrm{x}$ & $\mathrm{x}$ & $\mathrm{x}$ & $\mathrm{x}$ & $\mathrm{x}$ \\
\hline CXR or Chest CT & $\mathrm{x}$ & $\mathrm{x}$ & $\mathrm{x}$ & $\mathrm{x}$ & $\mathrm{x}$ & $\mathrm{x}$ & $\mathrm{x}$ & $\mathrm{x}$ & $\mathrm{x}$ \\
\hline Abdominal CT/MRI & $\mathrm{x}$ & $\mathrm{x}$ & $\mathrm{x}$ & $\mathrm{x}$ & $\mathrm{x}$ & $\mathrm{x}$ & $\mathrm{x}$ & $\mathrm{x}$ & $\mathrm{x}$ \\
\hline
\end{tabular}

Followup beyond 60 months, refer to text for more details. *For high- and very highrisk patients, consider an extended individualized followup. HX \& PE: history and physical examination. Blood test: include blood count, serum chemistries, and liver function test. CXR: can be alternated with chest CT. Low-risk: baseline CT at 3-12 months post-partial nephrectomy is optional. For ablation in cT1a tumours, surveillance is similar to low-risk disease except for abdominal CT/MRI at 3, 6, 12 
months then annually for up to 5 years. If patient is symptomatic or abnormal blood test, earlier radiological investigations may be indicated. 